\title{
Social implications of children's smartphone addiction: The role of support networks and social engagement
}

\author{
JENNIFER IHM* \\ School of Communications, Kwangwoon University, Seoul, Republica of Korea \\ (Received: November 22, 2017; revised manuscript received: February 12, 2018; second revised manuscript received: April 10, 2018; \\ accepted: April 19, 2018)

\begin{abstract}
Background and aims: Most studies have regarded smartphone addiction as a condition stemming from individuals' psychological issues, so research has rarely examined it in relation to a lack of social resources and its social impacts. However, this study reinterprets smartphone addiction as a social problem stemming from a lack of offline social networks and resulting in a decline of social engagement. Methods: This study drew on a survey of 2,000 children in Korea consisting of 991 males and 1,009 females with an average age of 12 years old. Using the STATA 14 structural equation modeling program, this study examined the relationships between children's lack of social networks, smartphone addiction, and social engagement. Results: Social network variables, such as formal organizational membership, quality of relationship with parents, size of the peer group, and peer support, decrease smartphone addiction. Simply having good relationships and reciprocal feelings with peers do not have any influence on the smartphone addiction. The more the children become addicted to smartphones, the less they participate in social engagement. Discussion and conclusions: This study provides a new understanding of smartphone addiction by focusing on its social aspects, augmenting prior studies that have addressed psychological factors. Findings suggest that children's lack of social networks may inhibit comfortable social interactions and feelings of support in the offline environment, which can heighten their desire to escape to smartphones. These children, unlike non-addicts, may not take advantage of the media to enrich their social lives and increase their level of social engagement.
\end{abstract}

Keywords: smartphone addiction, social networks, support networks, social engagement

\section{INTRODUCTION}

As smartphones have become an integral part of our lives, addiction to smartphones has also become a serious problem (Hwang \& Jeong, 2015). Researchers revealed that smartphone addiction has negative impact on individuals' psychological and physical health as well as academic and work performance (Kim, Min, Kim, \& Min, 2017; Park \& Lee, 2012; Samaha \& Hawi, 2016). In order to examine factors leading to smartphone addiction, previous studies have focused on psychological factors and found that stress, shyness, loneliness, anxiety, and depression are positively related to smartphone addiction (Chiu, 2014; Choi et al., 2015; Hong, Chiu, \& Huang, 2012; Samaha \& Hawi, 2016).

However, individuals' psychological traits may not explain every aspect of smartphone addiction. The research suggests that the psychological predictors of smartphone addiction may be closely related to social interactions and resources. Individuals addicted to smartphones use the media for social purposes (Van Deursen, Bolle, Hegner, \& Kommers, 2015). As they feel anxious and uneasy in offline interactions, they flee to smartphone interactions and become addicted to smartphones (Chiu, 2014; Lee, Chang, Lin, \& Cheng, 2014). However, if individuals possess rich social resources, they may receive psychological and social support from their networks and have more opportunities for offline interactions (Putnam, 2001). They may decrease their anxiety and uneasiness in offline social interactions and be less likely to escape to a smartphone [Although individuals with rich offline social networks may actively use media to maintain these offline relationships, they use media to complement offline interactions (Baym, 2010; Rainie \& Wellman, 2012); the support they receive from their rich offline networks may prevent them from substituting offline interactions for smartphone ones by escaping offline interactions to smartphone interactions. In this way, having offline social networks can indicate that individuals possess the resources to have comfortable offline interactions and to feel supported (Putnam, 2001), so that they do not need to escape the offline environment and become addicted to the smartphone environment.]. Therefore, a thorough understanding of smartphone addiction should go beyond psychological traits to examine individuals' social resources.

\footnotetext{
* Corresponding address: Jennifer Ihm; School of Communications, Kwangwoon University, Kwangwoon-ro 20, Nowon-gu, Seoul 01897, Republica of Korea; Phone: +82 2940 8248; Fax: +82 2918 3258; E-mail: ihmsy17@gmail.com
}

This is an open-access article distributed under the terms of the Creative Commons Attribution-NonCommercial 4.0 International License, which permits unrestricted use, distribution, and reproduction in any medium for non-commercial purposes, provided the original author and source are credited, a link to the CC License is provided, and changes - if any - are indicated. 
Because individuals who are addicted to smartphones are seeking easier interactions than those they experience in the real world, smartphones may have different impacts on their social lives than other individuals'. They may not use smartphones to increase their interactions and social engagement [This study focuses on civic aspects of social engagement and defines "social engagement" as engaging in civic activities, such as helping others in philanthropic organizations, participating in charity events, or volunteering for charitable causes (Campbell \& Kwak, 2010). This definition excludes activities of social interactions that are not tied to civic causes, such as seeing friends, going to places of worship, and visiting family.], as many others do (e.g., gathering useful information online to volunteer for charitable causes; Shah, Kwak, \& Holbe, 2001; Smith, Schlozman, Verba, \& Brady, 2009; Valenzuela, Park, \& Kee, 2009). Because previous studies have focused on psychological problems that smartphone addiction can cause (Hong et al., 2012; Samaha \& Hawi, 2016), they have rarely addressed its social outcomes. More attention to the social outcomes of smartphone addiction is necessary to understand the implications of smartphone addiction to society.

The purpose of this study is to examine the influence of social networks on smartphone addiction and the impact of smartphone addiction on individuals' level of social engagement. Specifically, this study focuses on children in Korea, where $79 \%$ of children aged $10-18$ years have smartphones (Korean Information Society Development Institute, 2014). Children are vulnerable to addiction to a new media (Gackenbach, 2011), and their social behaviors have an increasing impact on the societies in which they live as they grow (Drotner \& Livingstone, 2008; Putnam, 2001). In comparison to many studies on college students and adults (Kim et al., 2017; Park \& Lee, 2012; Samaha \& Hawi, 2016), the focus on children population may provide a unique perspective on smartphone addiction research.

\section{Social networks and smartphone addiction}

This paper focuses on three types of children's social networks. The first is formal organizational membership, such as belonging to voluntary or religious organizations, a prevalent measure of individuals' social networks (Putnam, 2001). Previous research suggests that formal organizational membership may provide feelings of support and security (Ihm \& Hsieh, 2015; Lin, Dean, \& Ensel, 2013), which are important factors to diminish media addiction (Samaha \& Hawi, 2016; Tsai et al., 2009). In comparison to many studies on psychological predictors of smartphone addiction (Chiu, 2014; Choi et al., 2015; Hong et al., 2012; Samaha \& Hawi, 2016), this study focuses on children's formal organizational membership in order to examine fundamental reasons of smartphone addiction that go beyond children's psychological traits.

The second is parental networks (including, hereafter, legal guardians). Most studies of smartphone addiction have focused on parent interventions and mediation in preventing smartphone addiction among the children, such as by restricting media use, setting rules for the amount of time and type of content viewed, and explaining and discussing the media (Ching \& Tak, 2017; Hwang, Choi, Yum, \& Jeong, 2017; Hwang \& Jeong, 2015). However, the research also suggests that parents may play an important role in preventing media addiction among children by providing feelings of security and support. For instance, a good parent-child relationship and deriving satisfaction from the relationship may prevent children's Internet addiction by diminishing their level of social anxiety (Lam, Peng, Mai, \& Jing, 2009; Liu \& Kuo, 2007), while parental attachment insecurity may heighten the risk of media addiction (Jia \& Jia, 2016). Therefore, this study examines how parental networks, instead of the direct mediation of parents in smartphone use, may prevent children from developing smartphone addiction.

The third is peer networks. The previous studies have explained the role of adults in children's smartphone addiction (Hwang \& Jeong, 2015), but fewer studies have paid attention to the role of peers in children's smartphone addiction. Children are more vulnerable to and conscious of their friends' approval and disapproval than their parents' or teachers' (Morrow, 1999), so children's peer networks may strongly determine children's behavior. While research focuses on the role of adult instruction in children's more meaningful use of media, children's peer networks may provide natural settings for comfortable offline interactions that lower the impulse to escape to a smartphone (Van Deursen et al., 2015). For instance, the feelings of being close to other peers may provide psychological security and comfort. Such psychological support may encourage children to stay connected with others without feeling awkward or insecure and therefore make them unlikely to escape to and become addicted to media (Caplan, 2005). Children's peer networks may also provide direct help and support when he/she is in trouble or in need (Lin et al., 2013; Putnam, 2001; Sarason \& Sarason, 2013); by offering actual resources as well as the feeling of belongingness to and security in their community, social support from peers may contribute to diminished media addiction (Tsai et al., 2009).

Peer network size may also be crucial in diminishing smartphone addiction. While parental networks largely consist of one to two people, the sizes of peer networks may vary. Children with a greater number of peers may use smartphones more actively to maintain their relationships, but the greater number of peers may also provide more diversity in psychological and social support as well as opportunities for natural offline interactions (Putnam, 2001; Tsai et al., 2009). In other words, children with a greater number of peer networks may use their smartphones to communicate with them but may not become addicted to or escape to a smartphone (Van Deursen et al., 2015). The first hypothesis addresses the three constructs of social networks; it runs as follows (see Figure 1 for a graphic representation of the hypotheses this article addresses):

Hypothesis 1. (a) Formal organizational membership, (b) parental networks, and (c) peer networks are negatively related to smartphone addiction. 


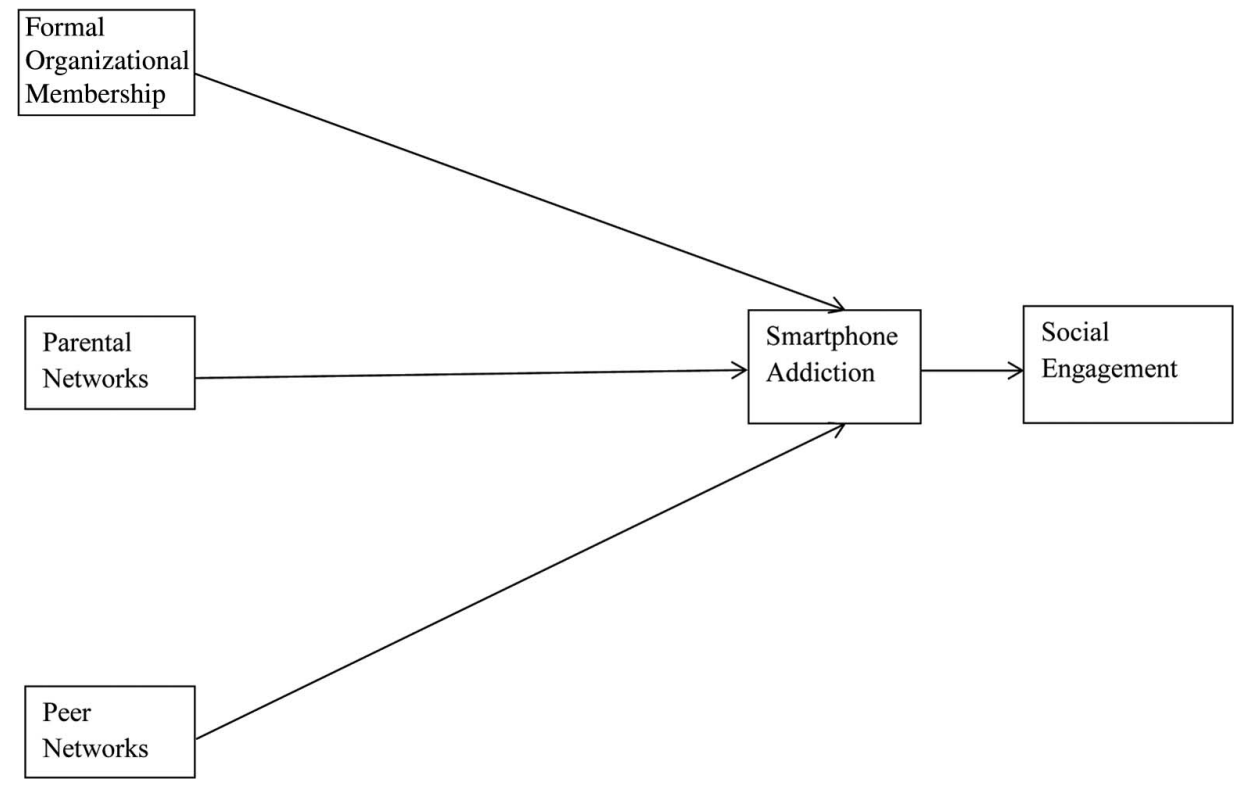

Figure 1. Hypothesized model

\section{Outcomes of smartphone addiction on social engagement}

Previous studies have demonstrated varied negative outcomes of media addictions. Media addiction generates psychological problems such as feeling worthless when not online or feeling lonely and depressed (Caplan, 2002, 2005; Young, 2004). Pragmatically, it also leads to ignoring responsibilities, managing time inefficiently, and low productivity (Caplan, 2002, 2005; Nalwa \& Anand, 2003; Tokunaga, 2014; Young, 2004). Smartphone addiction may also generate negative impacts both psychologically and practically, for example, through a low level of life satisfaction and academic performance, and high level of stress (Samaha \& Hawi, 2016).

However, the research has rarely addressed the influence of smartphone addiction on individual's social behaviors such as social engagement. Children's social engagement is essential for their psychological and physical well-being as well as the growth of democratic society (Drotner \& Livingstone, 2008; Putnam, 2001). Furthermore, while previous studies found that individuals, in general (instead of smartphone addicts), use new media to generate offline social engagement (e.g., volunteering, promoting social issues, rallying for political parties, or working on community projects) by gathering useful knowledge, information, or opportunities for the engagement (Shah et al., 2001; Smith et al., 2009; Valenzuela et al., 2009), these results may not apply to smartphone addicts. Because smartphone addiction is closely related to a desire to escape from offline social interactions (Caplan, 2005), smartphone addicts may not take advantage of smartphones to build offline social engagement; they may not participate in social activities, which require more active interactions and confrontation with others. As such, research is necessary to reveal how different population's use of smartphones might have different social outcomes in comparison to previous findings. Based on the negative impacts of smartphone addiction on individual well-being (Samaha \& Hawi, 2016) and media addicts' tendency to escape from social interactions (Caplan, 2005), this research hypothesizes a negative relationship between smartphone addiction and children's social engagement:

Hypothesis 2. Smartphone addiction is negatively related to social engagement. This section has explained social antecedents and outcomes of smartphone addiction. Focusing on children in Korea, this study conducts an empirical examination of the influence of social networks on smartphone addiction and the impact of smartphone addiction on their level of social engagement.

\section{METHODS}

\section{Sample and procedures}

The data for this study were drawn from the Child General Social Survey (Korean Statistical Information Service [KSIS], 2013), which was conducted by Korea Institute for Health and Social Affairs on behalf of the Ministry of Health and Welfare in the Republic of Korea. Under the enforcement ordinance of the Child Welfare Act Article 11, the institute carries out this national survey every 5 years to a stratified sample of households with children ages 0-17 years. For this survey, 600 regional clusters were chosen from every region of Korea, considering the representativeness of the regional characteristics (i.e., big city, small-medium city, or suburban area) and the children's age distribution. For each cluster, 27 households were chosen based on the children's age range (the oldest child was the focus, if the family had more than one) and the household income. Consequently, 417 general households and 250 low-income households for each age stratum (i.e., 0-2, $3-5, \ldots, 15-17$ years old) were chosen (see KSIS, 2013 for more details of the stratified sampling). Children aged 
9-17 years in the household were surveyed; younger children were excluded as their literacy might not be sufficient to complete it. The survey consists of questions about every aspect of children's lives including their physical and psychological health, family problems, characteristics, and media-use patterns. The scales in the survey had been translated and administered in Korean by the professional researchers from the institute. Professional researchers from the institute visit a national sample of households and guide the children through the survey. The data in this study were drawn from the most recent survey conducted from November 8 to December 15, 2013. The survey results are open to the public (KSIS, 2013) and the original data are available upon official request through the governmental portal (Open Data Portal, 2017). The sample consisted of 991 males and 1,009 females. The average age of the participants was about 12 years old $(N=2,000, M=12.25$, $S D=2.64)$ and their average daily smartphone usage time was $147 \min (S D=96.6)$.

\section{Measures}

Social networks. The survey measured various aspects of the children's social networks. Adapting a dichotomous measure from previous studies (Ihm \& Hsieh, 2015; Putnam, 2001), formal organizational membership was addressed in a question asking whether participants belonged to any offline organizations, such as "school clubs," "clubs from youth institutes or organizations," or "religious organizations" (1: yes, 0 : no; $N=2,000, M=0.49, S D=0.50$ ). For parental networks, the study used an amended measure of parental attachment (Jia \& Jia, 2016). The participants reported their range of agreement with eight statements from 1 (highly disagree) to 4 (highly agree) and their answers were averaged $(N=2,000, M=3.15, S D=0.61$, $\alpha=.91$; see Table 1 for full measures).

The participants also described their peer networks. The survey used measures adapted from prior research (Gottlieb \& Bergen, 2010; Marsden \& Campbell, 1984) to ask about their relationships with peers over the last year from 1 (highly disagree) to 4 (highly agree). This study conducted an exploratory factor analysis using principal axis factor extraction method with a Promax oblique rotation. The result revealed two distinct factors of peer networks. The first factor represented the degree of closeness with peers $(N=1,998, M=2.98, S D=0.68, \alpha=.88 ;$ Marsden \& Campbell, 1984), or peer closeness networks, such as

Table 1. Full measures of parental networks

\footnotetext{
Measures

"I talk with my parents a lot"

"I love my parents"

"My parents express a lot that they love me"

"My parents compliment me frequently"

"My parents are proud of me"

"I think I give energy to my parents"

"My parents gave me courage when I was going through hardships",

"My parents enjoy spending time with me"
}

good relationships and reciprocal feelings with their networks. The second factor represented the degree of actual support from their peer networks $(N=1,998, M=3.02$, $S D=0.52, \alpha=.75$; Gottlieb \& Bergen, 2010), or peer support networks (see Table 2 for full measures and the results of the factor analysis). In addition, the participants reported the size of their peer networks $(N=1,959$, $M=6.40, S D=4.83$ ).

Social engagement as smartphone addiction outcome. Eight items related to social activities were used to examine participants' level of social engagement. The activities included helping others in philanthropic organizations, making consolatory visits to orphanages or nursing homes, counseling or instructing younger generations, campaigning, participating in charity events, and volunteering for such causes as the environment and community development. Participants indicated whether they participated in each of eight activities (1: yes, $0:$ no; $\alpha=.71)$. The number of activities they participated in was recorded as the degree of social engagement $(N=2,000, M=0.65, S D=1.25)$.

Smartphone addiction. A scale consisting of 15 items on Internet addiction from a previous study (Caplan, 2010; $\alpha=.91$ ) was adapted to measure smartphone addiction. Caplan (2010) validated the Generalized Problematic Internet Use Scale 2 (GPIUS2) employing Anderson and Gerbing's (1988) two-step approach. The two-step approach consisted of empirically assessing operational and conceptual models of the scale. First, Caplan (2010) conducted a maximum likelihood confirmatory factor analysis (CFI) on the scale, which exhibited good construct validity as well as good discriminant and convergent validity. Next, the researcher validated the conceptual model of the measure by assessing the hypothesized relationships among the 15 items of the scale. The results from a structural equation modeling (SEM) with a maximum likelihood estimation showed an excellent fit, suggesting a nomological validity of the measures. This study changed the words in the GPIUS2, i.e., "online" or "Internet" to "smartphone" (e.g., "I use smartphone longer than I intended" and "If I cannot use the smartphone, I miss it so much that I am upset"). Participants indicated the degree of their agreement with the items (1: not at all, 4: very much) and their answers were averaged, following the

Table 2. Exploratory factor analysis of peer networks

\begin{tabular}{llcc}
\hline & \multicolumn{1}{c}{ Measures } & Factor 1 & Factor 2 \\
\hline Closeness & $\begin{array}{l}\text { "I am in a good } \\
\text { relationship with them" } \\
\text { "They have a good feeling } \\
\text { toward me" }\end{array}$ & $\mathbf{0 . 6 8}$ & 0.05 \\
& $\begin{array}{l}\text { "They help me when I am } \\
\text { in trouble" }\end{array}$ & 0.02 & $\mathbf{0 . 8 3}$ \\
Support & $\begin{array}{l}\text { "They stay with me when I } \\
\text { am lonely or having a }\end{array}$ & 0.05 & $\mathbf{0 . 8 2}$ \\
& $\begin{array}{l}\text { hard time" } \\
\text { Variance }\end{array}$ & 1.85 & 1.58 \\
Proportion & & 88.53 & 75.49 \\
\hline
\end{tabular}

Note. Values in bold in each column have primary loadings of at least 0.60 . 
Table 3. Correlations of key variables

(1)

(2)

(3)

(4)

(5)

(6)

(1) Smartphone addiction

(2) Social engagement

$-0.11^{*}$

(3) Formal organizational membership

(4) Peer network size

(5) Peer closeness networks

$-0.16^{*}$

(6) Peer support networks

$-0.12 *$

$0.27 *$

(7) Parental networks

$-0.16^{*}$

$0.11^{*}$

$0.13^{*}$

$-0.09^{*}$

$0.12 *$

$0.06^{*}$

$0.16^{*}$
$0.20^{*}$
$0.09^{*}$
$0.05^{*}$

$-$

$0.20^{*}$

$0.08^{*}$

$0.47 *$

$0.08^{*}$

$0.11^{*}$

Note. ${ }^{*} p<.05$.

way the scale was administered in the previous study $(N=$ $1,810, M=1.93, S D=0.47, \alpha=.88$; see Table 3 for correlations of key variables).

\section{Analysis}

All social network variables, the smartphone addiction measure, and the social engagement variable were combined into a single SEM (Figure 1). Two distinct factors of peer networks from factor analysis (i.e., peer closeness networks and peer support networks) were considered as latent variables in the model. This study analyzed the model by using STATA 14 SEM program (StataCorp, 2015 b) with maximum-likelihood estimates with missing values [Missing values in this study were missing at random (i.e., unrelated to other observed and unobserved variables), allowing for the option of "maximum likelihood estimates with missing values" in STATA software (StataCorp, 2015a).]. The final model [STATA program provides the goodness-of-fit of the entire model and a modification index for each possible parameter that was not specified in the original model. A large modification index indicates that adding the path to the model will likely improve model fit (StataCorp, 2015a). A typical procedure is to theoretically add defensible paths that have large modification indices one at a time, reviewing the results after the addition of each parameter (Byrne, 1998). The goodness-of-fit of the hypothesized model showed a lessthan-adequate fit, not meeting the criteria for root mean square error of approximation (RMSEA) value less than 0.05 ( $p$ value of close fit) and Tucker-Lewis index (TLI) greater than 0.95 (Hooper, Coughlan, \& Mullen, 2008): RMSEA $=0.13$, TLI $=0.89$. Therefore, a path was added to the hypothesized model according to the modification indices in conjunction with theory to determine whether addition of the path to the model is plausible. The modification indices showed that a path from formal organizational membership to social engagement would improve the model the most. Previous research also suggests that voluntary or religious organizational affiliations can act as important social capital that increases individuals' engagement in civic activities (Ihm \& Hsieh, 2015; Morrow, 1999; Putnam, 2001). Therefore, I added a path from formal organizational membership to social engagement in the model.] showed an excellent fit meeting the criteria for RMSEA value less than 0.05 ( $p$ value of close fit), $\mathrm{CMIN} / d f$ less than $3: 1$, and CFI greater than 0.95 , TLI greater than 0.95 (Hooper et al., 2008): RMSEA $=0.02$ $(p$ value of close fit $=.98), \mathrm{CMIN} / d f=1.62, \mathrm{CFI}=0.99$, $\mathrm{TLI}=0.98$. The ratio of sample size to the number of free parameters was 60.61. The coefficient of determination was 0.98 (Figure 2).

\section{Ethics}

This study is based on secondary data, drawn from the Child General Social Survey (KSIS, 2013), which was conducted by Korea Institute for Health and Social Affairs, conducted on behalf of the Ministry of Health and Welfare in the Republic of Korea.

\section{RESULTS}

Hypothesis 1 examined the relationship between social networks and smartphone addiction. Every social network variable but the closeness of the peer networks was negatively related to smartphone addiction (formal organizational membership: $\beta=-0.22, p<.001, S E=0.30$; parental network: $\beta=-0.21, p<.01, S E=0.31$; peer network size: $\beta=-0.17, p<.001, S E=0.04$; peer support network: $\beta=-0.32, p<.001, S E=0.35)$. Therefore, the set of hypotheses within Hypothesis 1 was supported except for a component of Hypothesis 1-c (peer closeness network).

Hypothesis 2 examined the outcome of smartphone addiction. Smartphone addiction was negatively related to social engagement $(\beta=-0.20, p<.05, S E=0.01)$. Therefore, Hypothesis 2 was supported.

\section{DISCUSSION}

This paper examined how social networks influence smartphone addiction and how smartphone addiction influences social engagement among children in Korea. The results suggest that social networks can prevent smartphone addiction by providing social support. They also suggest that smartphone addiction may negatively affect users' social engagement.

The results from Hypothesis 1 suggest that social networks can be important contributors to prevent smartphone addiction. In line with previous studies (Coleman, 1961; Putnam, 2001), belonging to clubs and religious organizations seems to provide children with a natural setting to get 


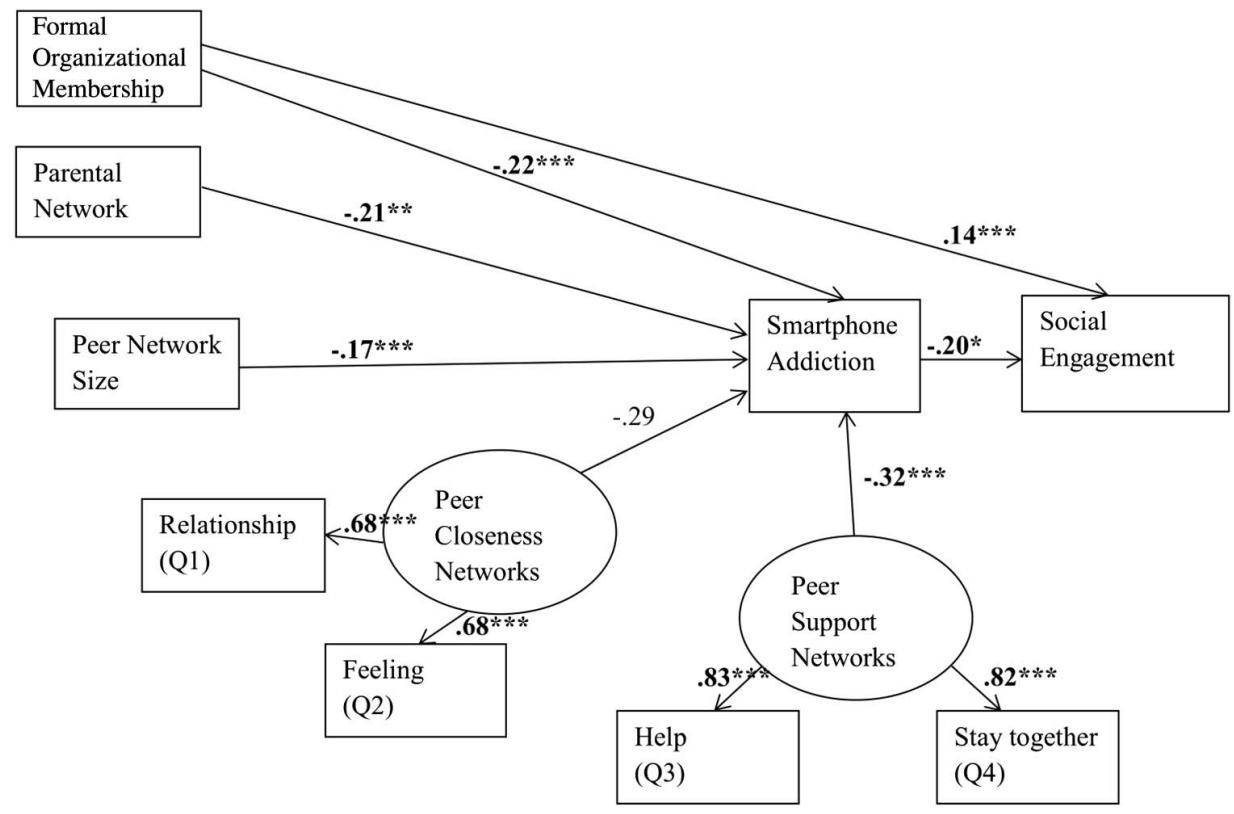

Figure 2. Final model. Note. To improve clarity and readability, covariance values are not reported. $(\mathrm{RMSEA}=0.2, \mathrm{CFI}=0.99, \mathrm{TLI}=0.98)$. ${ }^{*} p<.5 .{ }^{* *} p<.01 .{ }^{* * *} p<.001$

used to offline social interactions with varied people and feel connection with others; organizational affiliations seem to have a powerful impact in supporting children in comfortable offline interactions and lessening the need to escape to smartphones.

The results also suggest that children with large peer networks are less likely to be addicted to their smartphones than children with smaller size peer networks. Although individuals with large networks may actively use smartphones to maintain their relationships, large networks do not seem to enhance smartphone addiction but rather lessen it by providing more opportunities for comfortable interactions and feelings of security and support (Putnam, 2001; Tsai et al., 2009). As network size and formal organizational membership can represent diversity in networks, the two network constructs might fulfill various psychological and social needs to prevent escapism to smartphones, irrespective of their strength of ties (Granovetter, 1973).

Peer support networks had the strongest negative influence on smartphone addiction. This result supplements previous findings indicating that social support can play a role in preventing media addiction (Tsai et al., 2009). On the contrary, the peer closeness network was the only network variable that was not related to smartphone addiction. The results suggest that not all networks may diminish smartphone addiction; children seem to flee to smartphones not because they lack any social relationships (i.e., closeness networks) but because they are lacking in social support. This result suggests the value of examining different types of networks in investigations of their distinct influences on smartphone addiction.

Parental networks also had a negative influence on smartphone addiction. This result extends previous studies indicating that a good parent-child relationship may protect children from media addiction by lessening social anxiety and providing feelings of security, attachment, and support
(Lam et al., 2009; Liu \& Kuo, 2007). While previous studies have emphasized direct parental intervention in smartphone addiction (Ching \& Tak, 2017; Hwang \& Jeong, 2015; Hwang et al., 2017), this study suggests that having a good relationship with children may indirectly diminish smartphone addiction.

However, the effect of parental networks was relatively small in comparison to that of peer networks. The studies suggest that children do not always evaluate parental intervention as positive and that parental mediation may not be always articulated, justified, and expressed in a sensitive manner (Haddon, 2015). Children are rather more vulnerable to and conscious of their friends' approval and disapproval than their parents' or teachers' (Morrow, 1999). Despite previous research focuses on parental strict involvement (Hwang \& Jeong, 2015; Leung \& Lee, 2012), this result implies that securing children's autonomous peer networks might be more essential to prevent smartphone addiction beyond direct parental intervention.

The results from Hypothesis 2 suggest that smartphone addiction has a negative effect on children's social engagement. As children escape to and become addicted to smartphones, they do not participate in social activities. The negative influence provides social implications of media addiction above and beyond psychological and practical implications (Caplan, 2002, 2005; Samaha \& Hawi, 2016; Young, 2004). The results indicate that preventing smartphone addiction can be important in bringing up children as socially healthy citizens.

The results also enrich previous studies on the relationship between media addiction and social participation (Ellison, Steinfield, \& Lampe, 2007; Sarason \& Sarason, 2013). Whereas previous studies found that a greater degree of media use can contribute to social engagement, this study broadens previous scholarship by focusing on a minor population of smartphone addicts who cannot accomplish 
such positive outcomes by a greater degree of smartphone use. This difference calls for a more nuanced approach to different populations of media users that differentiating media types (e.g., social media and smartphone), purposes (e.g., information and entertainment), and activities (e.g., Internet surfing and instant messaging) in previous studies have not captured (Ellison et al., 2007; Park \& Lee, 2012; Shah et al., 2001; Smith et al., 2009; Valenzuela et al., 2009).

Overall, this study provides a new understanding of smartphone addiction by focusing on its social aspects, augmenting prior studies that have addressed psychological factors (Caplan, 2006; Hong et al., 2012; Kim \& Haridakis, 2009; Samaha \& Hawi, 2016; Tokunaga \& Rains, 2016). The results suggest that smartphone addiction may be a social problem resulting from a lack of social connections and resulting in a low level of social engagement. The results suggest that the importance of smartphone addiction inheres in its connections to offline society, such as offline social networks and social engagement.

\section{CONCLUSIONS}

This study represents one of the first examinations of the influence of social networks on smartphone addiction and the effect of smartphone addiction on social engagement. It has several limitations. It is based on a crosssectional survey, so causality cannot be determined. For example, there could be a reinforcing relationship between social networks, smartphone addiction, and social engagement. Because the study is based on secondary data, it could not pursue other interesting questions, such as the influence of online social networks on smartphone addiction, the influence of other network measures (e.g., centrality and density), or other predictors of smartphone overuse (e.g., stress and depression). This study also focused on offline social engagement, although the Internet and smartphones have expanded the concept of social engagement to include more distant or online involvement (Ihm, 2017; Lewis, 2013; Valenzuela et al., 2009). Furthermore, this study was based on children's self-reported responses only.

In light of the limitations of this study, future studies may include longitudinal research or may draw a more concrete picture of the relationship between social networks and social engagement and how this relationship might change or be reinforced over time. Future studies can also evaluate more detailed network measures (e.g., centrality and density; Monge \& Contractor, 2003) and describe other interesting links between social networks and smartphone addiction. Accounting and controlling for psychological causes of smartphone addiction (e.g., stress and depression), parents or guardians' perception of children's smartphone using behaviors, and online social engagement may provide a more comprehensive understanding of smartphone addiction. In addition, future research should examine how and why some children lack social resources and how interventions might focus on enriching support networks rather than diagnosing psychological symptoms.
Funding sources: The present research has been conducted by the Research Grant of Kwangwoon University in 2018.

Author's contribution: All works were done by JI.

Conflict of interest: The author declares no conflict of interest.

Acknowledgements: The author gratefully acknowledges the feedback from Yuli Patrick Hsieh and the anonymous reviewers.

\section{REFERENCES}

Anderson, J. C., \& Gerbing, D. W. (1988). Structural equation modeling in practice: A review and recommended two-step approach. Psychological Bulletin, 103(3), 411-423. doi:10.1037/ 0033-2909.103.3.411

Baym, N. K. (2010). Personal connections in the digital age. Malden, MA: Polity Press.

Byrne, B. M. (1998). Structural equation modeling: Basic concepts, application, and programming. Mahwah, NJ: Lawrence Erlbaum Associates.

Campbell, S. W., \& Kwak, N. (2010). Mobile communication and civic life: Linking patterns of use to civic and political engagement. Journal of Communication, 60(3), 536-555. doi:10.1111/ j.1460-2466.2010.01496.x

Caplan, S. E. (2002). Problematic Internet use and psychosocial wellbeing: Development of a theory-based cognitive-behavioral measurement instrument. Computers in Human Behavior, 18(5), 553-575. doi:10.1016/S0747-5632(02)00004-3

Caplan, S. E. (2005). A social skill account of problematic Internet use. Journal of Communication, 55(4), 721-736. doi:10.1111/ j.1460-2466.2005.tb03019.x

Caplan, S. E. (2006). Relations among loneliness, social anxiety, and problematic Internet use. CyberPsychology \& Behavior, 10(2), 234-242. doi:10.1089/cpb.2006.9963

Caplan, S. E. (2010). Theory and measurement of generalized problematic Internet use: A two-step approach. Computers in Human Behavior, 26(5), 1089-1097. doi:10.1016/j.chb. 2010.03.012

Ching, K. H., \& Tak, L. M. (2017). The structural model in parenting style, attachment style, self-regulation and selfesteem for smartphone addiction. Journal of Psychology \& Behavioral Science, 3(1), 85-103. doi:10.22492/ijpbs.3.1.06

Chiu, S. I. (2014). The relationship between life stress and smartphone addiction on Taiwanese university student: A mediation model of learning self-efficacy and social selfefficacy. Computers in Human Behavior, 34, 49-57. doi:10. 1016/j.chb.2014.01.024

Choi, S. W., Kim, D. J., Choi, J. S., Ahn, H., Choi, E. J., Song, W. Y., Kim, S., \& Youn, H. (2015). Comparison of risk and protective factors associated with smartphone addiction and Internet addiction. Journal of Behavioral Addictions, 4(4), 308-314. doi:10.1556/2006.4.2015.043

Coleman, J. S. (1961). The adolescent society. Oxford, UK: Free Press of Glencoe. 
Drotner, K., \& Livingstone, S. (Eds.). (2008). International handbook of children, media and culture. London, UK: Sage Publications.

Ellison, N. B., Steinfield, C., \& Lampe, C. (2007). The benefits of Facebook "friends": Social capital and college students' use of online social network sites. Journal of Computer-Mediated Communication, 12(4), 1143-1168. doi:10.1111/j.1083-6101. 2007.00367.x

Gackenbach, J. (Ed.). (2011). Psychology and the Internet: Intrapersonal, interpersonal, and transpersonal implications. Oxford, UK: Elsevier.

Gottlieb, B. H., \& Bergen, A. E. (2010). Social support concepts and measures. Journal of Psychosomatic Research, 69(5), 511-520. doi:10.1016/j.jpsychores.2009.10.001

Granovetter, M. S. (1973). The strength of weak ties. American Journal of Sociology, 78(6), 1360-1380. doi:10.1086/225469

Haddon, L. (2015). Children's critical evaluation of parental mediation. Cyberpsychology: Journal of Psychosocial Research on Cyberspace, 9(1), article 2. doi:10.5817/CP2015-1-2

Hong, F. Y., Chiu, S. I., \& Huang, D. H. (2012). A model of the relationship between psychological characteristics, mobile phone addiction and use of mobile phones by Taiwanese university female students. Computers in Human Behavior, 28(6), 2152-2159. doi:10.1016/j.chb.2012.06.020

Hooper, D., Coughlan, J., \& Mullen, M. (2008). Structural equation modelling: Guidelines for determining model fit. Electronic Journal of Business Research Methods, 6, 53-60.

Hwang, Y., Choi, I., Yum, J. Y., \& Jeong, S. H. (2017). Parental mediation regarding children's smartphone use: Role of protection motivation and parenting style. Cyberpsychology, Behavior, and Social Networking, 20(6), 362-368. doi:10.1089/ cyber.2016.0555

Hwang, Y., \& Jeong, S. H. (2015). Predictors of parental mediation regarding children's smartphone use. Cyberpsychology, Behavior and Social Networking, 18(12), 737-743. doi:10.1089/ cyber.2015.0286

Ihm, J. (2017). Classifying and relating different types of online and offline volunteering. International Journal of Voluntary and Nonprofit Organizations, 28(1), 400-419. doi:10.1007/ s11266-016-9826-9

Ihm, J., \& Hsieh, Y. P. (2015). The implications of information and communication technology use for the social wellbeing of older adults. Information, Communication and Society, 18(10), 1123-1138. doi:10.1080/1369118X.2015.1019912

Jia, R., \& Jia, H. H. (2016). Maybe you should blame your parents: Parental attachment, gender, and problematic Internet use. Journal of Behavioral Addictions, 5(3), 524-528. doi:10.1556/ 2006.5.2016.059

Kim, H. J., Min, J. Y., Kim, H. J., \& Min, K. B. (2017). Accident risk associated with smartphone addiction: A study on university students in Korea. Journal of Behavioral Addictions, 6(4), 699-707. doi:10.1556/2006.6.2017.070

Kim, J., \& Haridakis, P. M. (2009). The role of Internet user characteristics and motives in explaining three dimensions of Internet addiction. Journal of Computer-Mediated Communication, 14(4), 988-1015. doi:10.1111/j.1083-6101.2009. 01478.x

Korean Information Society Development Institute. (2014). 2013 broadcast communications trends. Retrieved from https:// www.kisdi.re.kr/kisdi/fp/kr/board/listSingleBoard.do? cmd=list SingleBoard\&sBoardId=BCAST_DB3
Korean Statistical Information Service [KSIS]. (2013). 2013 child general social survey. Retrieved from https://kosis.kr/eng/

Lam, L. T., Peng, Z. W., Mai, J. C., \& Jing, J. (2009). Factors associated with Internet addiction among adolescents. CyberPsychology \& Behavior, 12(5), 551-555. doi:10.1089/cpb. 2009.0036

Lee, Y. K., Chang, C. T., Lin, Y., \& Cheng, Z. H. (2014). The dark side of smartphone usage: Psychological traits, compulsive behavior and technostress. Computers in Human Behavior, 31, 373-383. doi:10.1016/j.chb.2013.10.047

Leung, L., \& Lee, P. S. N. (2012). The influences of information literacy, Internet addiction and parenting styles on Internet risks. New Media \& Society, 14(1), 117-136. doi:10.1177/ 1461444811410406

Lewis, L. K. (2013). An introduction to volunteers. In M. W. Kramer, L. K. Lewis, \& L. M. Gossett (Eds.), Volunteering and communication (pp. 1-22). New York, NY: Peter Lang Publishing Inc.

Lin, N., Dean, A., \& Ensel, W. M. (Eds.). (2013). Social support, life events, and depression. Orlando, FL: Academic Press.

Liu, C.-Y., \& Kuo, F.-Y. (2007). A study of Internet addiction through the lens of the interpersonal theory. CyberPsychology \& Behavior, 10(6), 799-804. doi:10.1089/cpb.2007.9951

Marsden, P. V., \& Campbell, K. E. (1984). Measuring tie strength. Social Forces, 63(2), 482-501. doi:10.1093/sf/63.2.482

Monge, P. R., \& Contractor, N. S. (2003). Theories of communication networks. New York, NY: Oxford University Press.

Morrow, V. (1999). Conceptualising social capital in relation to the well-being of children and young people: A critical review. The Sociological Review, 47(4), 744-765. doi:10.1111/1467954X.00194

Nalwa, K., \& Anand, A. P. (2003). Internet addiction in students: A cause of concern. CyberPsychology \& Behavior, 6(6), 653-656. doi:10.1089/109493103322725441

Open Data Portal. (2017). Child general social survey. Retrieved from www.open.go.kr

Park, N., \& Lee, H. (2012). Social implications of smartphone use: Korean college students' smartphone use and psychological well-being. Cyberpsychology, Behavior and Social Networking, 15(9), 491-497. doi:10.1089/cyber.2011.0580

Putnam, R. D. (2001). Bowling alone: The collapse and revival of American community. New York, NY: Simon and Schuster.

Rainie, L., \& Wellman, B. (2012). Networked: The new social operating system. Cambridge, MA: MIT Press.

Samaha, M., \& Hawi, N. S. (2016). Relationships among smartphone addiction, stress, academic performance, and satisfaction with life. Computers in Human Behavior, 57, 321-325. doi:10.1016/j.chb.2015.12.045

Sarason, I. G., \& Sarason, B. R. (Eds.). (2013). Social support: Theory, research and applications. Seattle, WA: Springer Science \& Business Media.

Shah, V., Kwak, N., \& Holbe, R. L. (2001). "Connecting" and "disconnecting" with civic life: Patterns of Internet use and the production of social capital. Political Communication, 18(2), 141-162. doi:10.1080/105846001750322952

Smith, A. W., Schlozman, K. L., Verba, S., \& Brady, H. (2009). The Internet and civic engagement. Washington, DC: Pew Internet \& American Life Project.

StataCorp. (2015a). Stata 14 base reference manual. College Station, TX: Stata Press. 
StataCorp. (2015b). Stata statistical software: Release 14. College Station, TX: StataCorp LP.

Tokunaga, R. S. (2014). A unique problem or the manifestation of a preexisting disorder? The mediating role of problematic Internet use in the relationships between psychosocial problems and functional impairment. Communication Research, 41(4), 531-560. doi:10.1177/0093650212450910

Tokunaga, R. S., \& Rains, S. A. (2016). A review and metaanalysis examining conceptual and operational definitions of problematic Internet use. Human Communication Research, 42(2), 165-199. doi:10.1111/hcre.12075

Tsai, H. F., Cheng, S. H., Yeh, T. L., Shih, C. C., Chen, K. C., Yang, Y. C., \& Yang, Y. K. (2009). The risk factors of Internet addiction - A survey of university freshmen. Psychiatry Research, 167(3), 294-299. doi:10.1016/j.psychres.2008.01.015

Valenzuela, S., Park, N., \& Kee, K. F. (2009). Is there social capital in a social network site?: Facebook use and college students' life satisfaction, trust, and participation. Journal of ComputerMediated Communication, 14(4), 875-901. doi:10.1111/ j.1083-6101.2009.01474.x

Van Deursen, A. J. A. M., Bolle, C. L., Hegner, S. M., \& Kommers, P. A. M. (2015). Modeling habitual and addictive smartphone behavior. Computers in Human Behavior, 45, 411-420. doi:10.1016/j.chb.2014.12.039

Young, K. S. (2004). Internet addiction. American Behavioral Scientist, 48(4), 402-415. doi:10.1177/0002764204270278 